\title{
¿Elecciones en Cuba?
}

Marcos Winocur

$\mathrm{P}$ ido disculpas por el carácter desordenado de estos apuntes que, en todo caso, no es mucho mayor que el de la política intemacional, tema necesario de tocar al abordar el asunto de las elecciones en Cuba.

Vivimos un momento histórico donde uno de sus rasgos es el avance de la derecha en muchos campos. Ante tal situación, la pregunta que surge no cuestiona el hecho consecuente del retroceso de la izquierda, sino su medida: ¿hasta dónde hacer concesiones?

Yo espero que no sea hasta encontrarse como si fuera al día siguiente de la Comuna de París, diciéndose: "nos quedan los ideales, la oportunidad histórica se ha perdido". Confio en que no y en que bien se trate de un recomenzar la continuidad de acontecimientos tan significativos como Rusia 1917, China 1949, Cuba 1959 o Vietnam 1975. Pero, aunque así no fuera, las convicciones permanecerán inalterables; la humanidad, si la dejan todavía un rato sobre el planeta, tendrá tiempo de averiguar por experiencia propia si son prematuras o no las voces de " $i$ el fin del comunismo, el fin del comunismo!"

Claro, una vezque pase el susto. Como si por un momento la humanidad retrocediera sin ánimos para emprender una tarea de la magnitud de la propuesta: abolir las clases, la subalternidad social, la explotación, con las cuales ha convivido por miles de años y que le ha forjado 
SECUENCIA
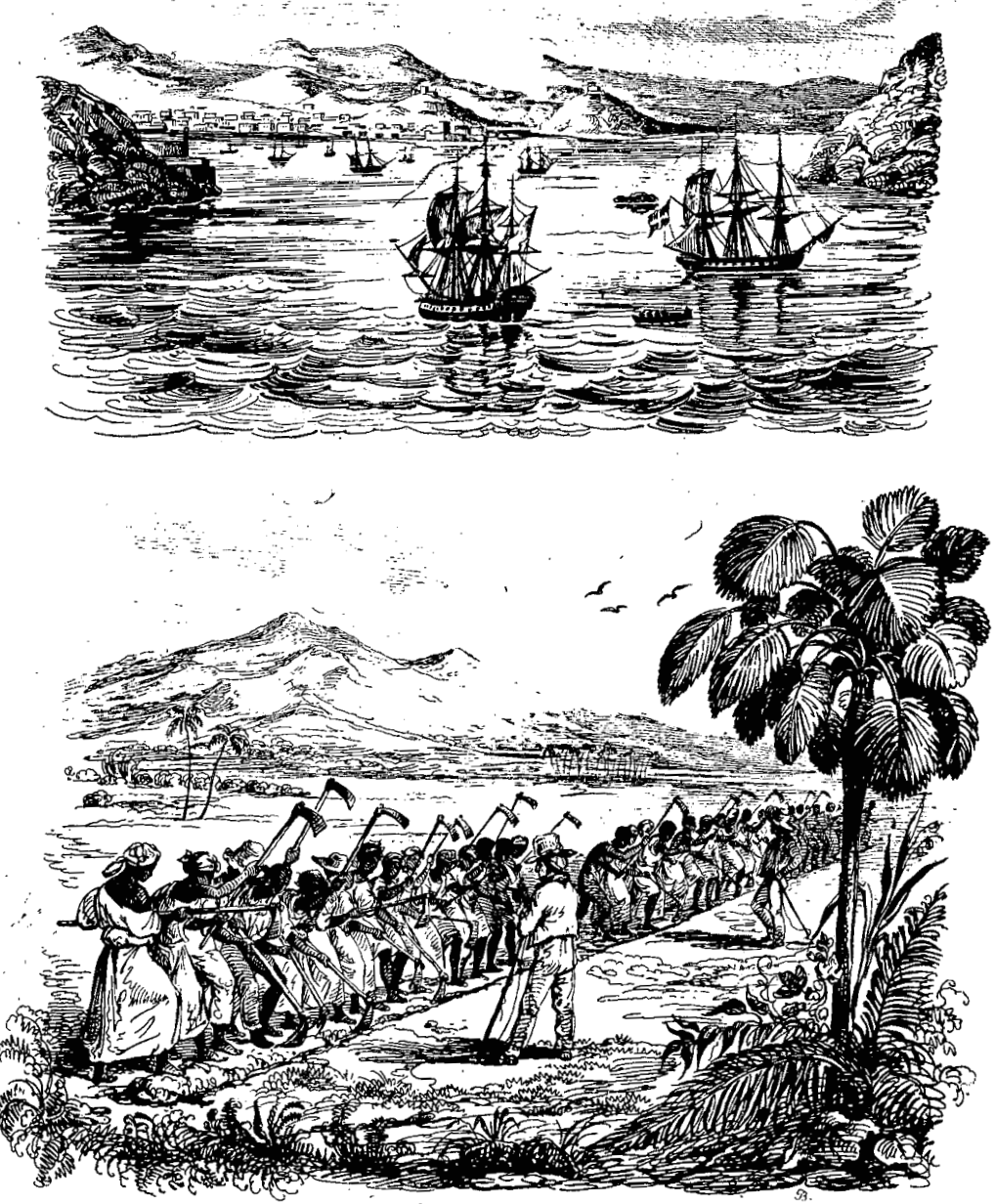
una mentalidad ad hoc... Si, existe hoy la capacidad de producir bienes para saciar a todos si a la ciencia y a la tecnología les dieran la oportunidad; de ningún modo es utopía.

Pero no: yo prefiero mi cotidiano consumo y la carrera por más, saltar el muro berlinés y del otro lado comprar el perfume francés. ¿Qué valor tendría éste el día en que todos los humanos tuvieran un perfume francés al alcance de la mano? Tal es la filosofía del consumo: refregarle en la cara al vecino que yo tengo y él no, "muérase de envidia señor vecino". Y así un día cambié el ideal del comunismo por la realidad del consumismo, voté por la democracia cristiana y salí a pintar cruces en los cementerios judíos.

En todo esto pueden sonar acentos pesimistas, pero así ocurre cuando los hechos tozudos se imponen a los sueños adolescentes, de los cuales el socialismo empieza apenas ahora a desprenderse. $Y$ digo comienza porque la actual fiebre democratista pertenece todavía a esos sueños. Hay quienes piensan que la revolución es cuestión de juntar un día a las gentes y preguntarles: ¿la quieren ono la quieren? Si levanta la mano $50 \%$ más uno, entonces se hace la revolución, en caso contrario se archiva. O bien se llama a plebiscito. Quienes están por la revolución coloquen una cruz en el casillero que reza sí...si ganan, se hace la revolución, en caso contrario se archiva. Tal es el error adolescente de signo contrario a otro no menos adolescente y padecido hasta hoy: si el partido de los comunistas se hace del Estado controlando policía y ejército, la revolución es un hecho. La experiencia de los países del este ha echado por tierra semejantes ideas. Pero, de considerar al partido como Superman se ha pasado al extremo contrario, considerar que de nada sirve y disolverlo. Son las condiciones históricas las que determinarán su suerte en cada país y no la voluntad o interpretación de los dirigentes. Un caso, el partido de los comunistas polacos: éste, o la organización o movimiento que haga sus veces, renacerá, no está excluido del seno del hasta hoy su mayor enemigo, Solidaridad. ¿Por qué? Porque alli están los obreros y ellos serán los más duramente golpeados a raíz de la restauración del capitalismo en su país.

¿Se acabaron las crisis económicas agudas y generalizadas a los países industrializados, se acabaron los peligros de las guerras y del fascismo, los fabricantes de armamentos reconvierten sus industrias y la bomba atómica pendiente sobre las cabezas de todos devuelve el juicio a los dirigentes de la política mundial...? Si la respuesta es positiva entonces es posible pensar la revolución en otros términos y la existencia misma de los partidos comunistas se coloca entre signos de interrogación. Ahora bien, esta discusión no es nueva y se remonta por lo menos al fin de la segunda guerra mundial cuando fue planteada por el dirigente de los comunistas americanos, Earl Browder; muchos de los argumentos que hoy se plantean, ya entonces fueron motivo de polémica.

Y bien, dentro del espectro del retroceso revolucionario, de situaciones imprevistas y de grandes cambios y discusiones se inscribe una nueva ofensiva sobre Cuba. Estados Unidos cree que ya arregló cuentas con Granada, Panamá y también es posible que lo piense respecto de Nicaragua; cree igualmente haberlo hecho con impunidad al punto de haber aislado a Cuba en la región, y cuenta con un debilitamiento en el apoyo que le presta la Unión Soviética a raíz delos acontecimientos vividos en el este.

Todo eso creen equivocadamente en Estados Unidos y la consecuencia no se 
hace esperar: redobla por todos los medios a su alcance la ofensiva sobre Cuba. Hasta hoy el recuento incluye un reforzamiento del bloqueo económico y la presión para que países aliados se plieguen al mismo; hostigamiento e intimidación a través de maniobras militares en la región; la instalación de la TVMartí para hacer conocer a los cubanos "la verdad" de cómo viven los cubanos. ¿Qué falta? Pues unas elecciones libres en la isla donde participen tanto los diferentes partidarios del socialismo y de la socialdemocracia como los liberales, democristianos, verdes, conservadores, neonazis. El gobierno dejará de interferir TV Martíy todos tendrán su tribuna; que gobierne quien más votos obtenga con el debido respeto a las minorías, como en la RDA.

¿Quién puede negar el papel que debe jugar la democracia dentro de la revolución y cómo aquélla fue desvirtuada en los países del este? La respuesta afirmativa a esta pregunta no puede hacer olvidar la diferencia: la democracia es un medio y la revolución es un fin.

Si la democracia me conduce a que Bush encuentre el cenit de su popularidad entre los americanos gracias a la invasión de Panamá; si unas elecciones libres son el vehículo para llevar a la democracia cristiana al gobierno de la República Democrática Alemana y a ser "unificada" ésta en la OTAN; si la democracia conduce a esa catástrofe en dos tiempos cuyos nombres son Alfonsín y Menem y cuyo efecto político inmediato es alentar el regreso de losgenerales...pues, bueno: reconozco los diversos procedimientos democráticos de Estados Unidos, Alemania Oriental y Argentina, pero afirmo seguidamente que de semejantes cosas los dioses protejan a Cuba.

Treinta años cumplidos de revolución... ¿ya es hora de convocar a elecciones pluripartidistas en Cuba? La revo- lución mexicana cumplía precisamente 30 años cuando Lázaro Cárdenas terminaba su mandato en 1940. Él había sido elegido bajo un sistema político de partidoúnicoy, de igual modo, se convocaban nuevos comicios presidenciales para designar a su sucesor; el momento revolucionario así lo exigía.

Claro, habrá que insistir, fue ese momento histórico como, salvadas las diferencias, es hoy el de Cuba; mi pretensión en modo alguno es generalizar. En otras situaciones dadas, la democracia parlamentaria al estilo tradicional y el pluripartidismo, han sido y continuarán siendo, herramientas de avance social. Fue dentro de este marco que se aprobaron la nacionalización del cobre en Chile, del petróleo en Venezuela, de la banca en México. Y muy variadas las suertes que corrieron: en Chile fue anulada mediante golpe de Estado y dictadura; en Venezuela se mantiene, en México está en camino de ser anulada en el marco de la misma democracia parlamentaria y pluripartidista que otrora la consagró. Tres nacionalizaciones, tres historias que son a la vez muestra de la conveniencia de no generalizar, de concretarse a la situación específica y, después de las elecciones en Nicaragua y de los cambios ocurridos en los países del este, hay que ahorrarse los vaticinios, sobre todo si son triunfalistas.

LaCuba prerrevolucionaria delos años cuarenta y principios de los cincuenta arroja un balance bastante negativo en cuanto a la democracia tradicional. El último de los regímenes constitucionales del presidente Carlos Prío Socarrás cayó en el desprestigio y en ese marco contribuyó a despejar el camino al golpe de Estado del general Fulgencio Batista, dictador entre 1952 y 1958 hasta el triunfo de Fidel Castro. Así, cuando éste asume la presidencia, la democracia tradi- 


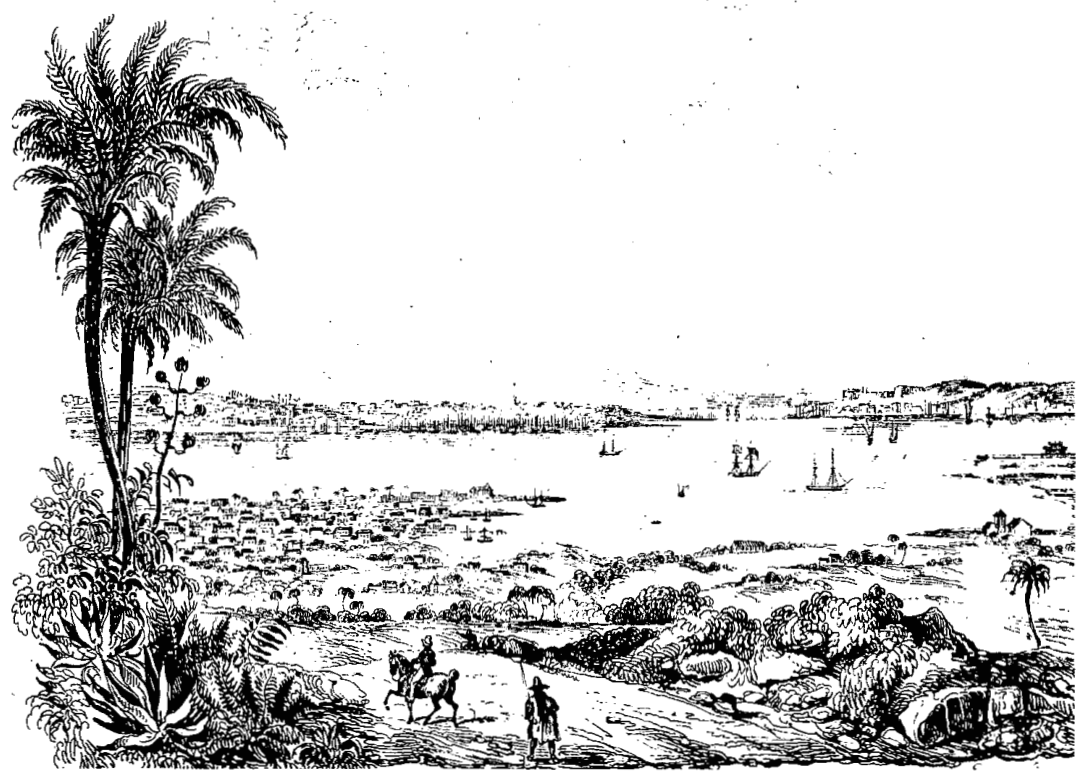

cional en Cuba llevaba un arrastre de desprestigio y el pueblo no reclamaba elecciones sino la apertura de un proceso de transformaciones revolucionarias. Asíse hizo, independientemente de aciertos y errores.

Vuelvo a lo mismo: la democracia no es un fin en sí misma, es un medio y, como tal, puede ser utilizado tanto para el avance social como, por la reacción, para servir a sus propios fines. Llamar en este momento a elecciones generales, a la manera democrática tradicional, es, en
Cuba -aun si Fidel Castro no las perdiera y el partido comunista conservara el poder-, contribuir a los fines de los reaccionarios y hacerles a éstos una concesión innecesaria y peligrosa para el curso de una revolución que tiene al poderosísimo y jurado enemigo a $180 \mathrm{~km}$ de sus costas.

Tal vez en un próximo momento histórico ya no lo sea; es imposible de prever. Mi balance llega hasta el día en que término estas páginas, 14 de mayo de 1990. Del futuro, el futuro dirá. 


\section{SECUENCIG}
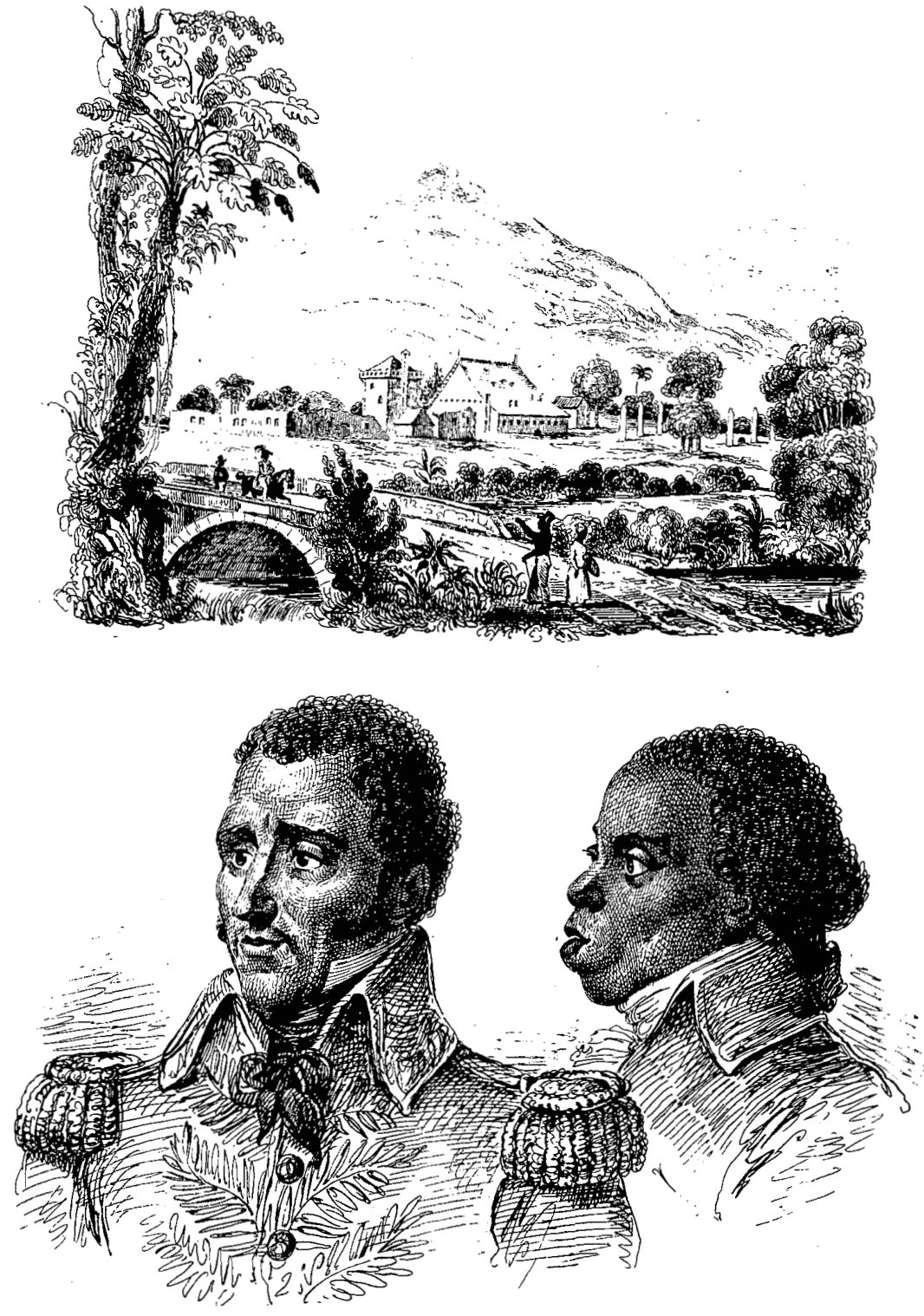